SCIO. Revista de Filosofía, n. ${ }^{\circ}$ 18, Julio de 2020, 177-204, ISSN: 1887-9853

\title{
VOLVER AL SENTIDO DE LA CIUDAD REFLEXIONES HERMENÉUTICAS Y ÉTICAS
}

\author{
BACK TO THE SENSE OF THE CITY \\ HERMENEUTICAL AND ETHICAL PERSPECTIVES
}

Francisco Arenas-Dolz $a^{a^{*}}$

Fechas de recepción y aceptación: 13 de noviembre de 2019 y 4 de junio de 2020

Resumen: El propósito de esta contribución es delinear las principales reflexiones sobre la ética de ciudad surgidas en los últimos años. Para ello se abordan, en primer lugar, las conexiones entre racionalidad práctica, urbanismo y espacio público desde la perspectiva del pragmatismo crítico y de la ciencia social fronética. Estas propuestas nos proporcionan el marco hermenéutico para presentar a continuación algunas de las aproximaciones éticas más relevantes que pueden aplicarse a las ciudades actuales: la ética de las virtudes urbanas, el derecho a la ciudad, el movimiento de la ciudad justa, el giro urbano de la ética, la ética del ambiente construido, la ética del diseño y la conducta medioambiental, el discurso ético sobre el Antropoceno y, por último, la ética de los comunes urbanos, mostrando su complementariedad y significado. Finalmente se resumen las conclusiones más relevantes del estudio, destacando la importancia de fomentar propuestas prácticas en el espacio público para habitar la ciudad de una manera más consciente, orientada a profundizar y fortalecer la democracia y sus fundamentos éticos.

Palabras clave: ciencia social fronética, espacio público, ética de la ciudad, hermenéutica crítica, justicia urbana, pragmatismo crítico.

${ }^{a}$ Facultat de Filosofia i Ciències de l'Educació. Departament de Filosofia. Universitat de València.

${ }^{*}$ Correspondencia: Universitat de València. Facultat de Filosofia i Ciències de l'Educació. Avenida Blasco Ibáñez, 30. 46010 Valencia. España.

E-mail: francisco.arenas@uv.es 
Abstract: The aim of this contribution is to outline the main reflections on the ethics of the city that have emerged in the last years. To this end, the connections between practical rationality, urbanism and public space will be firstly addressed from the perspective of critical pragmatism and phronetic social science. These proposals provide us with the hermeneutical framework to introduce then some of the most relevant ethical approaches that can be applied to today's cities: the ethics of urban virtues, the right to the city, the just city movement, the urban turn in ethics, the ethics of the built environment, the ethics of the environmental design and behavior, the ethical discourse of the Anthropocene and lastly the ethics of the urban commons, showing their complementarity and meaning. Finally, the most relevant conclusions of the study are summarized, emphasizing the importance of promoting practical proposals in the public space to inhabit the city in a more conscious way, aimed at deepening and strengthening democracy and its ethical foundations.

Keywords: phronetic social science, public space, ethics of the city, critic hermeneutics, urban justice, critical pragmatism.

Una ciudad está en sus ciudadanos, no en sus murallas.

Agustín (1995: 525)

El único factor material indispensable para la generación de poder es el vivir unido del pueblo. Solo donde los hombres viven tan unidos que las potencialidades de la acción están siempre presentes, el poder puede permanecer con ellos, y la fundación de ciudades, que como ciudades-estado sigue siendo modelo para toda organización política occidental, es por lo tanto el más importante prerrequisito material del poder.

ARENDT (2003: 224)

\section{$\S 1$. INTRODUCCIÓN}

Para los griegos la ciudad es la pólis, que según indica Aristóteles en varios lugares de la Política (3. 9, 1280b 31-35, 1280b 39-1281a 8; 7. 4, 1325b 36) es la comunidad de quienes son iguales en la virtud política y son capaces de 
mantener una constitución estable con el fin de vivir la mejor vida y la más feliz (Aristóteles, 1997: 85 y 117). Los romanos, en cambio, distinguen entre la civitas y la urbs. A propósito de esta distinción paradigmática Isidoro de Sevilla, en sus Etimologías (15.2. 1), señala: “Civitas (ciudad) es una multitud de personas unidas por vínculos de sociedad, y recibe ese nombre por sus ciudadanos (cives), es decir, por los habitantes mismos de la urbe, [porque concentra y encierra la vida de mucha gente]. Con el nombre de urbe (urbs) se designa la fábrica material de la ciudad, en tanto que civitas hace referencia, no a sus piedras, sino a sus habitantes" (Isidoro de Sevilla, 2004: 1059). Estos dos términos nos sitúan ante "la ciudad como sistema organizado de actividades humanas que ante todo crean las estructuras sociales y físicas que han de permitir su propio desarrollo y renovación" y ante "la ciudad como escenario físico dentro del cual los seres humanos desarrollan ciertas formas típicas de vida llamada «urbana»", perspectivas asociadas con un "paradigma histórico o biográfico" y con un "paradigma estructural o geométrico", respectivamente (Ramírez, 1998). La progresiva despolitización del término civitas en el mundo romano y el desarrollo de un amplio vocabulario urbano a partir del Medioevo tuvo como consecuencia que la civitas quedara ligada definitivamente a la urbs y a su imagen monolítica de asentamiento urbano.

Para nosotros sucede al revés: la ciudad es principalmente el entorno físico, no la comunidad humana. Esto es reflejo de la mentalidad tecnológica actual que otorga prioridad a lo físico, reduciendo la ciudad a mero artefacto visible, en lugar de atender al complejo de actividades humanas que se desarrollan en su seno. El objetivo de este trabajo es reflexionar sobre la ciudad contemporánea y articular distintas perspectivas hermenéuticas para recuperar el sentido de la ciudad. La condición urbana tiene dos significados principales: el primero designa tanto un territorio como un tipo de experiencia, de la que la ciudad es la condición de posibilidad; el segundo designa un espacio que antepone los flujos a los lugares, favoreciendo prácticas limitadas y segmentadas, como sucede en las megalópolis actuales (Mongin, 2006: 272). Para contrarrestar esta fragmentación, y ante las consecuencias de una globalización que divide, fragmenta y separa en lugar de reunir y relacionar, en este artículo se plantea la necesidad de recuperar la experiencia urbana como experiencia del lugar: la ciudad como una trama de lugares que juegan un papel significativo en las formas en que se organiza la experiencia cotidiana de la vida social, en línea 
con el pragmatismo crítico y la ciencia social fronética. La democracia debe devolverle a la condición urbana su primer sentido, contribuyendo a reducir aquellas desigualdades que socavan y disuelven la ciudad y a transformar los espacios en lugares cívicos, tal como plantean las distintas propuestas éticas sobre la ciudad.

\section{§2. RACIONALIDAD PRÁCTICA, PLANIFICACIÓN URBANA Y ESPACIO PÚBLICO}

Basándose en la teoría de la acción comunicativa habermasiana, John Forester (1993) ha desarrollado el pragmatismo crítico, un enfoque de planificación y de políticas públicas. La planificación es una actividad interactiva, comunicativa (Forester, 1987). Para este autor la planificación es el resultado de reestructurar la comunicación entre grupos de interés en conflicto y con grandes desigualdades de poder e influencia (Forester, 1989). Como acción comunicativa, la planificación se opone al modelo de racionalidad técnica y del análisis sistemático, adoptando la investigación una forma más cualitativa e interpretativa que trata de comprender lo contextual, más que alcanzar reglas generales para la práctica. Forester se distancia así de quienes subrayan en Habermas la centralidad del discurso racional modelado sobre los principios formales de la situación discursiva ideal y prefiere un tratamiento histórico y sustantivo de la esfera pública (Innes, 1995).

Apoyándose en la discusión de experiencias de terreno, Forester ha reflexionado también sobre las potencialidades y límites de los procedimientos deliberativos en la planificación y, en concreto, sobre el papel de los especialistas en los procesos de deliberación pública. La perspectiva del autor no se limita solo a lo que los planificadores hacen en la práctica, sino que se dirige a comprender cómo podrían hacer mejor su trabajo. El pragmatismo no es únicamente un recurso para la crítica, sino que considera que la reflexión debe calibrarse moralmente en la acción, generando conversaciones prácticas y recogiendo y transcribiendo historias útiles para el aprendizaje de estudiantes y profesionales. El pragmatismo crítico ha influido en el desarrollo de la investigación-acción participativa, método reflexivo y colaborativo para democratizar el conocimiento y, actuando en situaciones particulares, contri- 
buir al desarrollo comunitario. Según este enfoque, la actividad fundamental de los planificadores debería consistir en focalizar y conformar la atención, hablar y escuchar (Forester, 1999).

El planificador es un profesional práctico que facilita formas de acción colectiva inclusivas y participativas, en vez de un instrumentalista o decisionista racional, y desempeña un papel activo para alejar la planificación de los juegos del poder consecuencia de la posición social de los interlocutores y orientarlo hacia un proceso reflexivo y participativo transparente, examinando las mejores prácticas y aprendiendo de ellas. Cuando existen profundas diferencias valorativas los grupos de interés pueden alcanzar algunos objetivos comunes (Forester, 2009). Para lograrlos, Forester apela tanto al pragmatismo, con su insistencia en que el conocimiento surge de la experiencia, a partir de la cual vamos construyendo conceptos que interiorizamos, comunicamos y compartimos, sujetándonos a una regla, desde marcos que posibilitan el conocimiento, como al criticismo kantiano, que nos lleva a rastrear los errores e incoherencias en nuestras teorías para recategorizar las cosas, alejándonos de la ingenuidad.

Atendiendo a Habermas, en particular a su concepto de racionalidad comunicativa, Forester ha desarrollado una teoría del conocer que desafía la hegemónica epistemología de la Ilustración y apunta a una tradición más antigua, al pensamiento aristotélico sobre la sabiduría práctica. No obstante, el pragmatismo crítico de Forester presenta algunas limitaciones que tienen que ver precisamente con la idea de un proceso participativo transparente y con la dificultad de que todos los actores participen de manera libre y equitativa. Es necesario un compromiso previo de todos los participantes con los principios democráticos y el respeto a la diferencia, pues la participación pública puede en determinadas ocasiones legitimar modos hegemónicos de conocimiento o convertirse en una estrategia legitimadora de nuevos intereses.

El pragmatismo crítico ha inspirado otros estudios con acentos ligeramente diferentes: sobre la negociación y la construcción de consenso (Susskind y Cruikshank, 1987); sobre el discurso y la retórica (Throgmorton, 1991); sobre la representación (Peattie, 1987); sobre la construcción social del conocimiento (Innes, 1995); sobre el análisis y el discurso institucional y la planificación colaborativa (Healey, 1997). En todos estos trabajos, influidos tanto 
por la teoría habermasiana de la acción comunicativa como por los análisis foucaultianos sobre las conexiones entre conocimiento y poder, subyace una preocupación común por estudiar el potencial de opresión ínsito en la racionalidad instrumental y buscar modos de conocimiento más emancipadores (Howe y Kaufman, 1979; Hoch, 1994).

Estas conexiones entre conocimiento y poder han sido explicitadas por Bent Flyvbjerg. Frente a quienes se centran en la racionalidad comunicativa habermasiana y mantienen posiciones fuertemente normativas y procedimentalistas, prescindiendo de una compresión sustantiva de la racionalidad real, Flyvbjerg ha estudiado la influencia de las relaciones de poder en la evolución del desarrollo urbano y la importancia de la razón práctica para orientar la planificación urbana, proponiendo una síntesis del pensamiento de Aristóteles y Foucault que el autor define como "frónesis progresista" o "ciencia de lo concreto", en el contexto de una "ciencia social fronética" orientada a emplear la deliberación pública y la praxis de una manera efectiva en el ámbito de las ciencias políticas y la planificación urbana (Flyvbjerg, 1992). Las ciencias sociales han fracasado al emular el modelo de las ciencias naturales; por ello, sostiene Flyvbjerg, es necesario reconstruir las ciencias sociales desde el modelo de la phrónesis, pues solo este enfoque tiene en cuenta los valores, el poder y la centralidad de las personas y permitiría recuperar la importancia de la razón práctica para las ciencias sociales: “[...] el propósito de la ciencia social no es desarrollar teoría, sino contribuir a una racionalidad práctica de la sociedad, que elucide dónde estamos, a dónde queremos ir, y qué es deseable de acuerdo con los diversos conjuntos de valores e intereses" (Flyvbjerg, 2001: 167).

El punto de partida de la investigación fronética son los valores, no la fundamentación racional y universalista, anclando la investigación en el contexto estudiado, de forma que se produzca una fusión de horizontes entre todos los participantes. Flyvbjerg había aplicado antes esta propuesta teórica al diseño y planificación urbana en la ciudad danesa de Aalborg, apoyándose en el análisis de problemas concretos a partir del aprendizaje basado en proyectos. Según Flyvbjerg, el poder y la racionalidad se influyen mutuamente y forman los entornos urbanos en los que vivimos. El poder se ocupa de definir la realidad en lugar de descubrir qué es la realidad realmente; la racionalidad depen- 
de del contexto y el contexto de la racionalidad es poder; el poder utiliza con frecuencia racionalizaciones, a menudo difíciles de identificar como tales; cuanto más poder tiene un agente, menos se preocupa por dar razones: las relaciones de poder son producidas y reproducidas constantemente; las relaciones de poder estables son más típicas que las confrontaciones antagónicas; la razón encuentra dificultades en situaciones de relaciones de poder estables, pero tiene cierto margen de influencia, aunque en la confrontación abierta la racionalidad cede al poder. En definitiva, la democracia no es algo que una sociedad consigue de una vez por todas, sino que hay que ganársela día a día en los casos concretos (Flyvbjerg, 1998: 5). Por ello, este autor propone considerar el conflicto como el pilar de la democracia y de la planificación. Los investigadores fronéticos, más interesados en un enfoque que tome como punto de partida el conflicto y las relaciones de poder, desconfían del consenso a priori, pues con frecuencia este es fruto de ignorar el poder.

Apoyándose en la deliberación pública y en la esfera civil, los investigadores fronéticos evitan privilegiar el conocimiento de los expertos y tratan de adoptar prácticas más democráticas que fomenten la colaboración entre las distintas esferas. Son precisamente los investigadores fronéticos quienes se convierten en actores sociales virtuosos y comprometidos en sus ámbitos de estudio y, desde el conocimiento práctico de la sociedad, hacen política con su investigación. Sin embargo, dado que en la investigación fronética un aspecto importante son las relaciones de poder, es necesario que los conflictos entre las distintas esferas se reconozcan abiertamente y se negocien en un marco de colaboración (Flyvbjerg, Landman y Schram, 2012).

Tanto el pragmatismo crítico como la ciencia social fronética tratan de comprender la relación entre valores e intereses en la praxis y se alejan de la supuesta neutralidad del modelo cientificista de las ciencias naturales, reconociendo la necesidad de una ética capaz de enfrentar los desafíos de la planificación urbana para mejorar nuestras ciudades. En el contexto de la planificación urbana la deliberación cobra su sentido y adquiere su valor como un método de descubrimiento de aspectos valorativos y normativos que deben someterse a un profundo ejercicio reflexivo y ético para impulsar el cultivo de habilidades cívicas y democráticas y combatir así el empobrecimiento de la experiencia humana. 


\section{§3. ÉTICAS DE LA CIUDAD}

La urbanización a escala planetaria parece inexorable. Vivimos en un entorno cada vez más cambiante, en un "mundo como diseño" o un "segundo mundo" paralelo al natural, que también es completamente urbano. Sin embargo, se han descuidado en parte las implicaciones éticas de un mundo en rápida urbanización. ¿Cómo los cambios en los aspectos formales de las ciudades han transformado las condiciones de vida en ellas? ¿Cómo la urbanización ha creado nuevas categorías éticas, configurado nuevas identidades y relaciones morales? ¿Cómo, en definitiva, lo urbano ha configurado lo ético?

\subsection{La ética de las virtudes urbanas}

Desde la ética de las virtudes urbanas se ha insistido en la relación entre ética y arquitectura, presente en el propio término êthos, que significa inicialmente guarida, lugar donde habitan los animales, o morada, lugar donde habitan los hombres, y que después se entenderá como hábito, carácter o modo de ser. Las dos virtudes urbanas clave requeridas en la ciudad son la sociabilidad, que es cómo las personas pueden aprender a vivir con extraños y a tratar con personas que no se parecen a sí mismas, y la subjetividad, que es la forma en que la vida urbana puede moldear o civilizar la personalidad de un individuo a través de los vínculos asociativos que mantiene con los demás (Sennett, 2006).

La ciudad "remite a un tipo de conciencia" que "también puede representar la manera en que la gente desea que sea su vida colectiva" (Sennett, 2019: 10). Por eso, frente a la ciudad concebida como una jungla donde priman el egoísmo y el aislamiento, una ciudad abierta "debería tolerar las diferencias y promover la igualdad", así como "liberar del corsé de lo preestablecido y familiar, creando un ámbito en el que sus habitantes pudieran experimentar y expandir su experiencia" (Sennett, 2019: 19). La ciudad no tiene una imagen única, dominante, sino que es el resultado de ensamblar muchas imágenes distintas de maneras diferentes, incluso divergentes. La ética de una ciudad abierta se define por una riqueza de significados compartidos que hace po- 
sible vivir entre muchos: "La conexión ética entre el urbanista y el urbanita reside en la práctica de cierto tipo de modestia, en vivir entre muchos asumiendo el compromiso con un mundo que no es el espejo de uno mismo" (Sennett, 2019: 384). Es precisamente esta modestia la virtud que debería caracterizar la cooperación entre los planificadores urbanos y la gente y la que nos permitiría acotar la brecha entre la ville (urbs), el entorno construido por el especialista, que representa un entorno sólido, estable, y la cité (civitas), el espacio compartido por todos, que es líquida y variable. La responsabilidad de los expertos y la ética de una ciudad abierta radican en la coproducción del entorno construido. La ciudad es un lugar de intercambios informales que permite desarrollar prácticas dialógicas y de comunicación cooperativas, prácticas modestas capaces de transformar nuestra relación con la ciudad y orientarse al fortalecimiento de la comunidad.

Otras "virtudes cotidianas", por ejemplo, la decencia básica, el perdón, la compasión y la confianza, que permiten que diversas personas, pese a sus diferentes afiliaciones, vivan juntas pero separadas (Ignatieff, 2018), constituyen una respuesta inicial, aunque necesariamente incompleta, a los retos que plantea cómo crear un código ético compartido a pesar de las extremas diversidades y diferencias radicales que se encuentran en la ciudad multicultural actual.

Es importante identificar otros discursos que puedan reforzar la ética urbana. Cada uno de ellos se enmarca dentro de una tradición hermenéutica que comprende una multitud de conceptos y problemas, cuyo tratamiento requeriría un estudio muy detallado (Correa Casanova, 2019). La pólis se dice de muchas maneras, cada una relacionada con una visión distinta de la ciudad, de los ciudadanos y de la ciudadanía, del gobierno y del bien común, que apuntan a una determinada idea de convivencia, de justicia social, de desarrollo. En este sentido, la ética de la ciudad es la ética de las personas que la componen y, por tanto, la ética de sus ciudadanos. Si el ser humano es un ser en relación, la ética de la ciudad debería tener como propósito cultivar los vínculos de interdependencia, responsabilidad recíproca y solidaridad y promover, custodiar y propiciar lo humano común, centrándose en el cuidado del otro y favoreciendo, frente a una cultura de la indiferencia y los conflictos identitarios, una cultura de la proximidad y de la amistad cívica, de la escucha 
y de la acogida del otro, que se traducen en una llamada a respetar los derechos humanos y los principios democráticos.

El enfoque que defendemos aquí considera necesario conjugar diferentes perspectivas sin olvidar las posiciones de quienes abogan por una ciudad justa y sitúan la ética en las oportunidades que ofrecen los procesos de urbanización, en la disminución de las diferencias y desigualdades de los habitantes. A continuación se presentarán algunas de estas perspectivas: el derecho a la ciudad, el movimiento de la ciudad justa, el giro urbano de la ética, la ética del ambiente construido, la ética del diseño y la conducta medioambiental, el discurso ético sobre el Antropoceno y la ética de los comunes urbanos.

\subsection{El derecho a la ciudad}

El concepto "derecho a la ciudad" surgió en 1968, cuando Henri Lefebvre publicó El derecho a la ciudad, una reflexión sobre los problemas socioespaciales urbanos (Lefebvre, 2017). Tras examinar el impacto negativo sufrido por las ciudades en los países de economía capitalista - privatización de los espacios urbanos, uso mercantil de la ciudad, predominio de las industrias, degradación ambiental, fragmentación de la vida en común-, Lefebvre define el derecho a la ciudad como el derecho de los habitantes urbanos, principalmente de la clase obrera, aunque más adelante incluirá también a otros grupos de interés, a construir, decidir y crear la ciudad, frente a la enajenación y despolitización que el urbanismo moderno ha producido en la sociedad. Si lo que caracteriza a las ciudades tradicionales es el "habitar", que confiere a los ciudadanos identidad urbana y capacidades para la participación política, los procesos de urbanización convierten el "habitar" en "hábitat", en ocupar una vivienda, alejando a los ciudadanos de la acción política.

Para Lefebvre los ciudadanos son los auténticos protagonistas de la ciudad, la ciudad es el espacio político por excelencia para realizar una vida común, no exenta de conflictos. La obra de este autor es una profunda reflexión sobre el sentido de la ciudad, tema al que dedicó también los libros Espacio y política (Lefebvre, 1976) y La producción del espacio (Lefebvre, 2013), pu- 
blicados en 1972 y 1974, respectivamente. Lefebvre considera que la ciudad se ha convertido en un producto que se puede comprar y vender, colonizada por el valor de cambio, e insiste en la importancia de entender la ciudad como una obra y de recuperar el valor de uso del espacio urbano y el derecho a la apropiación de este espacio para que vuelvan a ser los habitantes quienes determinen las decisiones que afectan sus vidas.

El interés por la perspectiva lefebvriana ha experimentado un auge considerable a raíz de la crisis económica de 2008 y está asociado a las movilizaciones sociales y a la exigencia de derechos ciudadanos. Ha sido retomada, por ejemplo, por los movimientos sociales y por los organismos de cooperación para crear espacios políticos y democratizar las decisiones. En el contexto de una mayor globalización económica y de un aumento de las contradicciones sociales urbanas, David Harvey ha planteado el derecho a la ciudad como una posibilidad social de lucha. En un contexto como el actual, de mejores condiciones tecnológicas para diseñar la ciudad, el empobrecimiento de la experiencia urbana y la restricción de la participación dificulta el acceso a la ciudad a la mayoría de sus habitantes, limitando el acceso ciudadano a las decisiones sobre la ciudad e impidiendo "diseñar un planeamiento urbano integral" (Harvey, 2007: 386).

Para Harvey "la urbanización capitalista tiende a destruir la ciudad como bien común, social, político y vital” (2013: 125), fomentando procesos de "neoliberalización" de las ciudades y una serie de transformaciones orientadas a la fragmentación, privatización y securitización de los espacios urbanos, de los que la gentrificación sería un ejemplo paradigmático. Sobre estos presupuestos, y desde un planteamiento marxista dispuesto a superar los problemas de sobreacumulación, Harvey reinterpreta el derecho a la ciudad como un derecho humano parte de una estrategia de lucha anticapitalista capaz de incidir en la gestión urbana, criticando así las insuficiencias del planteamiento lefebvriano: "[...] el derecho a la ciudad tiene que plantearse, no como un derecho a lo que ya existe, sino como un derecho a reconstruir y recrear la ciudad como un cuerpo político socialista con una imagen totalmente diferente, que erradique la pobreza y la desigualdad social y que cure las heridas de la desastrosa degradación medioambiental" (Harvey, 2013: 202). 


\subsection{La ciudad justa}

La noción de "ciudad justa" es un concepto que ha sido desarrollado en el ámbito de las políticas urbanas por Susan S. Fainstein (2010). Por una parte, Fainstein evita proponer una teoría de la ciudad ideal y, en su lugar, busca "desarrollar una teoría urbana de la justicia y usarla para evaluar instituciones y programas existentes y potenciales". Por otra parte, y siguiendo el sentido contextual de la justicia propuesto por Harvey, su análisis solo se acota al "contexto actual de la urbanización capitalista en los países occidentales ricos, formalmente democráticos" (2010: 5). La autora desarrolla principios de justicia aplicables al urbanismo que reconozcan la naturaleza situacional de la valoración ética.

Los principios de una ciudad justa son tres: equidad, diversidad y democracia. Con estos principios, Fainstein pretende posicionarse entre las teorías liberales, en particular John Rawls, y las teorías marxistas, en particular David Harvey. Frente al concepto de igualdad, Fainstein aboga por la "equidad distributiva". Frente al concepto de tolerancia, Fainstein prefiere la "diversidad", con raíces en el pensamiento de Jane Jacobs, que respaldó la mezcla de usos del suelo como factor de vitalidad de las ciudades, o de Richard Sennett, que se opuso a la segregación en las grandes ciudades, o también de Iris Marion Young, que resaltó la importancia de la diferencia como criterio de justicia social. La democracia se refiere a la participación de los ciudadanos en la toma de decisiones sobre planes y proyectos urbanos. Frente a una idea de participación ciudadana con un carácter básicamente defensivo, es importante fomentar el debate moviendo a los participantes a ir más allá de sus intereses particulares y alcanzar unos resultados justos, desde una visión amplia de la ciudad.

La aplicación del criterio de equidad en la toma de decisiones urbanas nos lleva a repensar la relación entre justicia social y justicia espacial, asunto importante en la tradición iniciada por Lefebvre y en las obras de autores como David Harvey y Edward W. Soja. Una dimensión crucial en nuestra sociedad es el espacio, donde se arraiga la justicia. Comprender las interacciones entre el espacio y la sociedad es fundamental para comprender las injusticias sociales y planificar políticas orientadas a reducirlas. Esta reivindicación de la 
justicia espacial y del derecho a la ciudad incluye otras dimensiones, como el género, la etnicidad o la cultura, que evidencian la diversidad de formas de experimentar la ciudad.

La ciudad solo es la expresión física de formas de dominación elaboradas por una sociedad en un momento de su historia. Así, en las sociedades cortesanas del antiguo régimen las desigualdades y las injusticias se ocultaban tras la proximidad territorial (Elias, 1993). La ciudad estaría formada por la sedimentación urbana de culturas pasadas. Sin embargo, es un error pensar que las injusticias sociales pueden eliminarse actuando sobre las formas urbanas. Si bien se pueden cuantificar las desigualdades, no pasa lo mismo con la injusticia. El sentimiento de injusticia depende del punto de vista no solo del observador, sino de los observados. La ciudad injusta es aquella donde las clases sociales desfavorecidas no consiguen una redistribución equitativa de las rentas y están excluidas de los procesos de toma de decisión, no logrando el reconocimiento de su identidad colectiva (Young, 2000).

Una sociedad injusta tendrá siempre como producto una ciudad injusta. Por ello es necesario pensar la ciudad no como una estructura autónoma, independiente, esencializada, sino como encajada en un sistema social y cultural y caracterizada por la vulnerabilidad de los grupos sociales marginados y la capacidad del sistema urbano para adaptarse a los acontecimientos, especialmente a las grandes catástrofes, como desastres naturales y guerras, y reorganizarse. Así, la construcción social del espacio público ha de prestar atención a los diferentes discursos sobre las ciudades y a la manera en que cada uno de ellos incrementa las desigualdades -racismo, fundamentalismo religioso, discriminación por razón de género, injusticia ambiental-, con el propósito de contrarrestarlas y dar respuesta a las demandas de justicia espacial en contextos de diversidad urbana, creando relaciones espaciales justas y democráticas. El espacio, tradicionalmente considerado en su dimensión física, es una fuerza activa que moldea nuestra experiencia (Soja, 2008; 2014).

La ciudad no es solo un objeto, sino una construcción social. Así, construir una ciudad implica una forma de pensar. Hénaff (2016) distingue tres momentos en la construcción de la ciudad: la ciudad monumento, entendida como lugar sagrado; la ciudad máquina, entendida como dispositivo de producción; la ciudad red, entendida como espacio de conexión, circulación e 
intercambios. Esta última es la ciudad que viene, una ciudad delirante, lugar de lo indefinido, frente a la cual Hénaff reclama hacer ciudades con justicia y dignidad.

\subsection{La ética urbana}

Enfoques más recientes se han centrado en los factores sociales, culturales y políticos que pueden conducir a la formación de una ética urbana. Los defensores de la "ética urbana" reclaman la inseparabilidad de las esferas ética y política en el contexto del diseño urbano. A diferencia del énfasis más restringido en la justicia entre los partidarios de la ciudad justa, la ética urbana implica una preocupación mayor por una serie de desafíos urbanos, como la descarbonización, la desigualdad y la responsabilidad en la gobernanza urbana. La ética urbana ha provocado una conexión sin precedentes entre la política, la ética, la planificación y el diseño urbano.

Loïc Wacquant, por ejemplo, ha estudiado la desigualdad urbana y la marginalización y ha analizado a partir de estudios empíricos cómo ciertas construcciones teóricas y políticas urbanas han sido incapaces de superar estos problemas. El desempleo de larga duración, la proliferación del precariado, la estigmatización, el desamparo por parte del Estado y la extinción de las redes de apoyo vecinales e institucionales ha hecho resurgir en las sociedades profundas desigualdades, que han alimentado la expansión de ideologías racistas y tensiones xenófobas. Estas marginalidades avanzadas, caracterizadas como el "nuevo régimen de relegación socioespacial y de cerrazón excluyente [...] que se ha cristalizado en la ciudad posfordista como efecto del desarrollo desigual de las economías capitalistas y de la desarticulación del Estado de Bienestar" (Wacquant, 2007: 13), han llegado a formas de segregación e inequidad espacial.

Otros autores, como Peter Marcuse, han insistido no solo en la ciudad justa, sino también en la ciudad buena. Si en una ciudad justa se considera la justicia desde una dimensión distributiva en relación con cierto tipo de igualdad, una ciudad buena no se caracteriza, a juicio de este autor, simplemente por la equidad distributiva, sino más bien por promocionar el desarrollo de todos y 
cada uno de los individuos (Marcuse, 2009). Para él la ciudad no existe como unicidad, como modelo único, sino que hay muchos modelos de ciudad. Por ello es necesario hablar menos del espacio urbano, del espacio público y más sobre los espacios urbanos, los espacios públicos.

Sin embargo, hablar de "la" ciudad justa o de "la" ciudad buena no contribuye a fomentar el pensamiento crítico sobre las formas de producción del espacio y corre el riesgo de convertirse en un mito que otorgue legitimidad a quienes lo han fabricado y consideran que la urbanización representa una fuerza vital capaz de moldear el bienestar humano en un futuro inmediato. La desigualdad en el espacio no se relaciona solo con deficiencias en materia de vivienda y hábitat, sino también con nuevos mecanismos de diferenciación de las prácticas espaciales de sus habitantes. Esto resulta fundamental para repensar las políticas urbanas de reducción de la desigualdad. Es necesario analizar las desigualdades socioespaciales en términos multidimensionales (Owen, 2009). La arquitectura ha cumplido una función comunicativa, ha sido un medio para contar una historia sobre quienes la construyen, ha estado encaminada a crear una realidad alternativa que los poderosos quieren que veamos (Sudjic, 2007). A diferencia de los lugares habitados, donde las relaciones se basan en identidades establecidas, lo urbano se caracteriza por su heterogeneidad y complejidad, como espacio donde se enfrentan perspectivas antagónicas sobre la esfera pública. Este carácter abierto de lo urbano, proclive a los conflictos y exclusiones, no es posible fijarlo por los expertos -políticos, planificadores, arquitectos-. Los espacios urbanos reflejan las relaciones entre géneros y responden a un determinado orden social que influye en quienes ocupan un lugar determinado y quienes quedan excluidas de él.

Otros autores proponen hablar de una "ciudad ética", la ciudad planificada según un marco ético, capaz de enfrentar de manera crítica y responsable problemas globales como la aparición de nuevas enfermedades y la devastación de los ecosistemas (Barrett, Horne y Fien, 2016). Para desarrollar este modelo resulta fundamental generar la conciencia en la población de la importancia que tienen sus acciones. Promover no solo "construcciones cívicas", sino también desarrollar la perspectiva cívica de una manera integral, plantea una importante renovación metodológica que fomente los procesos colaborativos entre la academia, las empresas, las organizaciones de la sociedad civil y las 
administraciones públicas desde un enfoque de abajo arriba que contribuya a fortalecer las habilidades cívicas y democráticas y a generar innovadoras dinámicas sociales para enfrentar los desafíos actuales. Estudiantes y futuros planificadores urbanos deberían sumergirse directamente en la ciudad y practicar un urbanismo itinerante centrado no solo en observar la ciudad, sino también en escuchar los problemas de los habitantes del lugar y las soluciones que ellos mismos sugieren. Solo desde ahí es posible leer la ciudad en su estado actual y dar indicaciones para transformarla, además de despertar un auténtico interés por el desarrollo cívico en la ciudadanía. Aquí resultaría especialmente útil recuperar la concepción experiencial del urbanismo que Patrick Geddes expresó en su obra Ciudades en evolución, publicada en 1915, donde considera que la "ciencia cívica" consiste precisamente en saber que las instituciones y los edificios se levantan desde dentro; no son impuestos desde arriba ni construidos desde afuera (Geddes, 2009).

\subsection{La ética del ambiente construido}

La ética del ambiente construido se ha desarrollado en las últimas dos décadas en conexión con la ética ambiental para corregir el sesgo predominante en esta última, que ha privilegiado el medio natural frente al medio urbanizado (Fox, 2000). Con el término "ambiente construido" nos referimos a los espacios modificados por el ser humano y que son un producto cultural del trabajo humano. Se trata de un ámbito interdisciplinario de estudios basado en el derecho, la economía, la salud pública, la psicología, la geografía, la planificación, el diseño, la tecnología o las ciencias ambientales, que tiene como objetivo fomentar el bienestar de la comunidad mediante mejoras estéticas y medioambientales en el paisaje, en la salud o en las formas de vida: el acceso a una alimentación sana, la presencia de parques y jardines comunitarios en determinados barrios, etc. Frente a los proyectos urbanísticos promovidos por intereses a corto plazo (Kirkman, 2010), la ética del ambiente construido exige una mayor colaboración entre políticos, planificadores, arquitectos, ambientalistas y ciudadanos. Un aspecto importante en esta perspectiva es la representación cognitiva del ambiente, la valoración ambiental y la influencia del medio construido en nuestros comportamientos y actitudes. Por esta razón 
es importante desarrollar una ética situada, que en los procesos de toma de decisión tenga en cuenta las características el lugar (Mugerauer y Manzo, 2008).

Frente a la presunta objetividad de la arquitectura moderna, orientada a la ausencia del espacio y del lugar, la función ética de la arquitectura consiste en articular un modo de ser distintivo, que exprese las características del lugar (Harries, 1997). Desde esta comprensión de la arquitectura como una disciplina ética y de diseño, vinculada a una manera de entender la vida, los valores y la ética profesional, otros autores han propuesto organizar la ética de la arquitectura en torno a tres ejes: conciencia, comprensión y elecciones, estudiando los problemas éticos en la arquitectura desde cinco perspectivas: programa, producción material, estética, ideologías y praxis, y reivindicando la responsabilidad -económica, social, medioambiental- en el ejercicio profesional (Wasserman, Sullivan y Palermo, 2000). Desde otras perspectivas se ha articulado una ética de la arquitectura recuperando la tríada vitruviana: firmeza (firmitas), utilidad (utilitas) y belleza (venustas) (Spector, 2001).

Es necesario diseñar ciudades vivibles cercanas a los ciudadanos, ciudades comprensibles o legibles, que permitan sentar las bases para una ciudad humana, definida como una red de sendas, hitos, mojones, límites y barrios. Una ciudad legible será aquella donde los ciudadanos den significado a los lugares frecuentados: "No somos tan solo observadores de este espectáculo, sino que también somos parte de él, y compartimos el escenario con los demás participantes" (Lynch, 2008: 10). Por ello es importante tomar en consideración en la planificación urbana a todos los grupos de interés, organizar mapas complejos para saber dónde estamos, comprender el espacio, las capas históricas y desarrollar la experiencia estética de la ciudad.

Gracias a la invención de las ciudades, las sociedades han progresado en mayores cotas de libertad, prosperidad y bienestar económico y social. Las ciudades nos permiten convivir con los demás y socializarnos, compartir experiencias, cooperar y aprender. De ahí la importancia de las ciudades como fuente de innovaciones y generación de conocimientos. El éxito de las ciudades está ligado a la calidad del capital humano. Una ciudad no prospera construyendo grandes infraestructuras, sino satisfaciendo las demandas de la gente. Es necesario impulsar iniciativas locales para resolver los problemas de la gente, pues el conocimiento local y concreto, que no poseen los burócratas, es fundamental para encontrar soluciones viables (Glaeser, 2011). 


\subsection{La ética del diseño y la conducta medioambiental}

La ética del diseño y la conducta medioambiental se basa en dos ideas centrales: en primer lugar, lo político es inseparable de lo ético en el contexto de la ciudad; en segundo lugar, la ética podría movilizarse a través del diseño espacial para imaginar realidades urbanas en términos distintos de los actuales. En un mundo caracterizado por la volatilidad financiera y geopolítica, los desplazamientos de población, las crisis ambientales y las olas de protesta, las ciudades son espacios democráticos para imaginar y pensar el futuro y desarrollar nuevas formas de subjetividad, pertenencia, identidad y ciudadanía (Mostafavi, 2017).

En contextos donde la inexistencia de los espacios públicos es un hecho, desde la invasión de calles y plazas públicas con la publicidad hasta la comercialización de los medios de comunicación de masas, que ha llegado a debilitar el tejido social, es importante recuperar otras perspectivas sobre el espacio público que permitan entenderlo como un ágora, un lugar de encuentro donde se produzca intercambio de argumentos y no compraventa de mercancía, donde todas las posiciones puedan tener voz y donde el ejercicio de la participación sea parte de un proceso más amplio, articulado con otras formas de acción colectiva (Jacobs, 2011). En un artículo publicado en 1979 el historiador y crítico inglés Kenneth Frampton se apropia de la ambigüedad encontrada en el diccionario al definir la arquitectura como "conjunto de construcciones y edificios" y como "arte de proyectar y construir edificios", identificable con la distinción arendtiana entre la labor y la acción, para entender la arquitectura no solo desde su objeto (labor), sino también por su capacidad para adquirir un sentido que traspase la mera instrumentalidad (acción) (Frampton, 1979).

Conviene recordar que en La condición humana Arendt desarrolla su teoría de la vida activa, que se constituye como la conjunción de las actividades humanas de labor, trabajo y acción. En su explicación de la pólis griega, o en su idealización, como apuntan algunos críticos, Arendt señala que esta no debe entenderse en términos de localización física, sino como resultado del discurso y la acción, a través de los cuales los hombres hacen su "aparición" en el mundo. Las palabras y actos expresan la cualidad humana de la pluralidad y son la manera como los seres humanos se presentan unos a otros en 
cuanto hombres. El espacio público, que es el "espacio de la aparición”, es el escenario de la acción política, "un espacio entre los participantes que puede encontrar su propia ubicación en todo tiempo y lugar" (2003: 221). Según Arendt, la peculiaridad de este espacio "consiste en que, a diferencia de los espacios que son el trabajo de nuestras manos, nos sobrevive a la actualidad del movimiento que le dio existencia" (2003: 222), la condición primera de su existencia radica en el acontecimiento del discurso y la acción, donde todos los hombres aparecen explícitamente unos a otros. Arendt construye su concepción de lo político desde esta metáfora teatral y así entiende el espacio público como un espacio de aparición complejo, dinámico, donde interactúan el actor y el espectador, que ejercitan su capacidad de juicio, y donde las instituciones están siempre sujetas a revisión.

Esta noción de "espacio de la aparición" vinculada en Arendt a una comprensión performativa del espacio público, es la que llevó a Frampton en 1983, en pleno auge de la arquitectura posmoderna, a elaborar el concepto de "regionalismo crítico" con el propósito de superar la indiferencia hacia el lugar en la arquitectura moderna, empleando elementos contextuales para enriquecer los significados de la arquitectura (Frampton, 2002). A diferencia del regionalismo, que intenta reproducir miméticamente la arquitectura vernácula, sin prestar atención a los elementos universales, el regionalismo crítico, según Frampton, tendría que adoptar de manera crítica la arquitectura moderna, sin perder de vista los elementos contextuales, pero dándoles un sentido inédito que, al hacernos conscientes de la pérdida del lugar, nos lleve a la reflexión y nos ponga en relación con lo universal. En consecuencia, y frente a la posmodernidad, que considera fracasado el proyecto moderno y postula una vuelta atrás, el regionalismo crítico sostendría, en línea con Habermas, que la modernidad es un proyecto incompleto.

A partir de las intersecciones entre la noción arendtiana de "espacio de la aparición" y la propuesta de Chantal Mouffe (2007) de recuperar la dimensión agonista del espacio público frente al modelo deliberativo de democracia y las limitaciones de la esfera pública, Frampton se ha posicionado en defensa de una "arquitectura pluralista categóricamente opuesta a aquella de la espectacularidad estilística y hegemónica de la visión del mundo neoliberal" (Frampton, 2013). Contra una arquitectura espectacular, orientada a 
la creación de íconos, caracterizada por la indiferencia hacia el lugar y la falta de identidad, dirigida a fortalecer la hegemonía, estabilizar y dominar, la opción agonista de Frampton contribuye a crear espacios para la discusión y el pluralismo que permitirían formular nuevas categorías políticas y diálogos para la acción capaces de radicalizar las instituciones democráticas. Un acercamiento agonista al espacio público nos facultaría para identificar temas naturalizados y considerar que es la interdependencia la que nos constituye políticamente y nos permite pensar otras formas de habitar (Butler, 2017). Desde esta perspectiva se problematiza la tensión entre la búsqueda de unidad en el ámbito político y el peligro de la atomización del individuo.

\subsection{El discurso ético sobre el Antropoceno}

El Antropoceno designa una nueva época geológica caracterizada por la transformación humana de los sistemas planetarios, cuya primera manifestación sería el cambio climático. El término fue acuñado por el químico atmosférico Paul J. Crutzen, galardonado con el Premio Nobel por sus trabajos sobre la capa de ozono, y el limnólogo Eugene F. Stoermer, quienes en un artículo publicado en 2000 propusieron la hipótesis del Antropoceno (Crutzen y Stoermer, 2000). Aunque el cambio climático es la manifestación más llamativa de esta transformación, hay otros fenómenos igualmente importantes, en los que se muestra que la naturaleza y la cultura están profundamente vinculadas: la urbanización, la agricultura industrial, la pérdida de la biodiversidad, la modificación genética de organismos, los avances tecnológicos, etc. Este carácter dual del Antropoceno, como término geológico y cultural, representa una excelente oportunidad para explorar nuevas formas de colaboración inter- y transdisciplinaria.

Desde el discurso ético sobre el Antropoceno se considera que la ciudad puede ser tanto una fuente potencial para contrarrestar los impactos negativos del cambio climático como la causa de muchas formas contemporáneas de precariedad. En este sentido la tarea más importante de la ética debería ser transformar nuestras actitudes y crear nuevas formas para diseñar y vivir en el mundo. Una ética de la ciudad no puede limitarse a políticas urbanas cosmé- 
ticas, epidérmicas y cortoplacistas, sino que ha de tener en cuenta el impacto del cambio global en el Antropoceno (Chan, 2019). Una ética de la ciudad ha de ser crítica y denunciar la instrumentalización de una sostenibilidad que se ha convertido en dogma sin saber muy bien qué significa. Algunas voces han denunciado esta instrumentalización y han reflexionado sobre el urbanismo en la era del cambio climático con el propósito de hacer más naturales nuestros entornos urbanizados (McHarg, 2000; Rose, 2018). Por ejemplo, Rose (2018) presenta una serie de buenas prácticas en torno a cinco cualidades que debe cumplir la ciudad bien temperada: coherencia, circularidad, resiliencia, comunidad y compasión, que podrían ayudarnos a repensar a fondo el sentido de la ciudad.

\subsection{La ética de los comunes urbanos}

Otras perspectivas han contribuido a comprender la ciudad como el espacio donde compartir recursos que implican retos en su gestión, mantenimiento y acceso. Así, los trabajos de Elinor Ostrom (2000) sobre las normas de gobernanza de las que se dotan las comunidades para gestionar los recursos comunes han influido en los modos de repensar la gestión colectiva de los recursos urbanos de uso común. Estos comunes urbanos se pueden clasificar en materiales -viviendas, espacios públicos, espacios verdes- e inmateriales -conocimiento, cooperación, seguridad-, naturales -agua, aire, tierra- y artificiales -sociales, culturales-, etc. Entre los casos de estudio más frecuentes se encuentran huertos urbanos, jardines comunitarios, programas de vigilancia vecinal, sistemas de distribución de agua, de electricidad o de recolección y tratamiento de desechos, mercados callejeros, parques y otras instalaciones recreativas, casas ocupadas o cooperativas de viviendas. Más allá de ser considerados simplemente como recursos, estos "comunes vecinales" deben estar acompañados de una comunidad activa que los gestiona, dotándose de normas compartidas, y del apoyo del Gobierno local, que los regula y hace sostenible su uso (Foster, 2011).

Los comunes urbanos plantean una crítica radical al individualismo al proyectar estrategias innovadoras para fortalecer la cohesión social mediante la 
creación de redes descentradas y colaborativas. Algunos autores han señalado que los nuevos comunes digitales permitirían dar soluciones a retos en el ámbito local y generar procesos de cocreación distribuida y abierta. La aparición de internet ha cambiado las formas de relacionarse en las ciudades y ha propiciado el surgimiento de laboratorios cívicos orientados al desarrollo local, capaces de abordar muchos de los desafíos de las sociedades contemporáneas en los ámbitos social, cultural, económico y ambiental, a través de soluciones alternativas y sostenibles a los problemas sociales mediante el compromiso cívico y la participación de los sectores público y privado. Por ejemplo, William J. Mitchell (2000) ha acuñado el concepto "ciudad de bits" para referirse a las ciudades inteligentes como lugares complejos donde las tecnologías de la información y la comunicación permitirían desarrollar nuevas formas de relación más abiertas y compartir de manera gratuita recursos y experiencias que potenciaran las sinergias entre las administraciones públicas, las empresas, el mundo académico y la sociedad civil, con el fin de generar y compartir el conocimiento. Sin embargo, la ciudad digital es un espacio de posibilidades y riesgos, por lo que conviene preservar las cualidades de la ciudad tradicional y de sus espacios públicos, en especial aquellos espacios que permitan desarrollar prácticas modestas orientadas al desarrollo de la comunidad, pues sigue siendo ineludible la función del tejido asociativo en la tarea de crear conocimiento local y dar a las personas la oportunidad de contribuir activa y cooperativamente a generar bienes públicos gratuitos y a disposición de todos. Crear un verdadero espacio público, más cooperativo, sensible y autocrítico, es la forma que una ciudad abierta tiene para afirmar las libertades fundamentales.

\section{§4. Consideraciones finales}

La urbanización es uno de los fenómenos y desafíos clave del siglo XXI. Más de la mitad de la población mundial vive ya en áreas urbanas y es probable que la proporción alcance el 70 \% de la población en 2050. Sin embargo, se está perdiendo el arte de pensar la ciudad en función de necesidades racionales y de orientarla hacia una manera de vivir marcada por el respeto al otro, la convivencia, el uso democrático de lo disponible, el aprendizaje progresivo 
de la cohabitación con la diferencia, en fin, ese conjunto de sistemas y de relaciones sociales y culturales que nos constituye como personas y hace factible la realización humana.

Pensar la ética y la política desde la ciudad, a partir de la consideración filosófica sobre la novedad que supone la ciudad contemporánea, implica promover la participación ciudadana en las decisiones y la gestión y compartir los bienes sociales disponibles para democratizar el poder y las condiciones de acceso al conocimiento. La ciudad del futuro debe estar compuesta no solo por hombres y mujeres que piensen de modo diferente, sino también que sean capaces de discrepar civilizadamente. La heterogeneidad es un componente principal de la ciudad.

Tanto el pragmatismo crítico de Forester como la ciencia social fronética de Flyvbjerg reconocen que, en el ámbito de la planificación urbana, el conocimiento contextual no es accesible desde la teoría sola, sino que uno de los elementos clave consiste en trabajar en contextos reales y reflexionar sobre experiencias surgidas de las prácticas de las múltiples iniciativas de la sociedad civil. Proyectos educativos orientados a leer la ciudad como un texto que debe ser interpretado nos permitirían reconectar los saberes curriculares con el mundo y vincular la experiencia subjetiva con las condiciones objetivas que impone el mundo, para contribuir así a la formación de una ciudadanía activa, participativa y responsable en el ámbito de nuestras ciudades.

Entre los retos de la ciudad a la ética está articular las redes locales y los intereses de la gente para generar nuevas dinámicas y paradigmas que permitan mantener los vínculos sociales, recuperar espacios y tiempos para la convivencia y restablecer la relación con la naturaleza. Esto supone organizar, de manera interdisciplinaria y transdisciplinaria, ideas útiles para la ciudadanía, fomentando la interacción de la teoría y la práctica, y ofrecer respuestas a los desafíos cívicos actuales, desde una perspectiva participativa e innovadora, potenciar la innovación social, combinando la experiencia concreta, la observación y la reflexión, además de promover la colaboración entre gobiernos, empresas, academia y comunidades. En este sentido, las distintas aproximaciones éticas a la ciudad presentadas en este trabajo, así como los marcos éticos que las sustentan, son perspectivas complementarias, aunque a veces se hayan querido presentar como alternativas y excluyentes. 
En conclusión, comprender la vida social urbana no es un asunto solo de expertos. La participación ciudadana resulta ineludible en el proceso de proyectar y diseñar una ética de la ciudad y promover un urbanismo pensado a una escala más humana. Desde estas coordenadas, el diseño urbano es un proceso hermenéutico que debería plantearse como una instancia crítica para interpretar la realidad viviente e imaginar un futuro posible al que llegar tras una negociación de abajo arriba, fruto del trabajo participativo y del compromiso social, dirigiéndose a los problemas de las comunidades locales a las que pertenecemos, $\mathrm{y}$ hacerlo de manera significativa.

\section{REFERENCIAS BIBLIOGRÁFICAS}

Agustín (1995). La devastación de Roma. En Obras completas de San Agustín, XL, 515-529. Madrid: Biblioteca de Autores Cristianos.

Arendt, H. (2003). La condición humana. Barcelona: Paidós.

Aristóteles (1997). Política. (J. Marías \& M. Araújo, Trads.) Madrid: Centro de Estudios Políticos y Constitucionales.

Barret, B., Horne, R., Fien J. (2016). The Ethical City: A Rationale for an Urgent New Urban Agenda. Sustainability, 8(11), 1-14.

Butler, J. (2017). Cuerpos aliados y lucha politica. Hacia una teoría performativa de la asamblea. Barcelona: Paidós.

Chan, J. K. (2019). Urban Ethics in the Anthropocene: The Moral Dimensions of Six Emerging Conditions in Contemporary Urbanism. Singapore: Palgrave Macmillan.

Correa Casanova, M. (2019). Hacia una ética de la ciudad. En E. GonzálezEsteban, J. C. Siurana Aparisi, J. L. López-González y M. García-Granero (eds.), Ética y democracia. Desde la razón cordial (pp. 251-269). Granada: Comares.

Crutzen, P. J. \& Stoermer, E. F. (2000). The 'Anthropocene'. Global Change Newsletter (41), 17-18.

Elias, N. (1993). La sociedad cortesana. México: Fondo de Cultura Económica. 
Fainstein, S. S. (2010). The Just City. Ithaca, NJ: Cornell University Press.

Flyvbjerg, B. (1992). Aristotle, Foucault and Progressive Phronesis: Outline of an Applied Ethics for Sustainable Development. Planning Theory (7-8), 65-83.

Flyvbjerg, B. (1998). Rationality and Power: Democracy in Practice. Chicago: The University of Chicago Press.

Flyvbjerg, B. (2001). Making Social Science Matter: Why Social Inquiry Fails and How It Can Succeed Again. Cambridge: Cambridge University Press.

Flyvbjerg, B., Landman, T., Schram, S. (eds.). (2012). Real Social Science: Applied Phronesis. Cambridge: Cambridge University Press.

Forester, J. (1987). Critical Theory and Public Life. Cambridge, MA: MIT Press.

Forester, J. (1989). Planning in the Face of Power. Berkeley: University of California Press.

Forester, J. (1993). Critical Theory, Public Policy, and Planning Practice: Toward a Critical Pragmatism. Albany: State University of New York Press.

Forester, J. (1999). The Deliberative Practitioner. Cambridge, MA: MIT Press.

Forester, J. (2009). Dealing with Differences: Dramas of Mediating Public Disputes. Oxford: Oxford University Press.

Foster, S. R. (2011). Collective Action and the Urban Commons. Notre Dame Law Review, 87(1), 57-133.

Fox, W. (ed.). (2000). Ethics and the Built Environment. London: Routledge.

Frampton, K. (1979). The Status of Man and the Status of His Objects: A Reading of The Human Condition. En M. A. Hill, From Hannah Arendt: The Recovery of the Public World (pp. 101-130). New York: St. Martin's Press.

Frampton, K. (2002). Hacia un regionalismo crítico. Seis puntos para una arquitectura de resistencia. En H. Foster, La posmodernidad (pp. 37-59). Barcelona: Kairós.

Frampton, K. (2013). Towards an Agonistic Architecture. Domus (972), 1-8. Geddes, P. (2009). Ciudades en evolución. Oviedo: KRK. 
Glaeser, E. (2011). El triunfo de las ciudades. Cómo nuestra mejor creación nos hace más ricos, más inteligentes, más ecológicos, más sanos y más felices. Madrid: Taurus.

Harries, K. (1997). The Ethical Function of Architecture. Cambridge, MA: MIT Press.

Harvey, D. (2007). Espacios del capital. Hacia una geografía crítica. Madrid: Akal.

Harvey, D. (2013). Ciudades rebeldes. Del derecho a la ciudad a la revolución urbana. Madrid: Akal.

Healey, P. (1997). Collaborative Planning: Shaping Places in Fragmented Societies. Vancouver: University of British Columbia Press.

Hénaff, M. (2016). La ciudad que viene. Santiago de Chile: LOM ediciones.

Hoch, C. (1994). What Planners Do: Power, Politics and Persuasion. Chicago: American Planning Association.

Howe, E., Kaufman, J. (1979). The Ethics of Contemporary American Planners. Journal of the American Planning Association, 45(3), 243-255.

Ignatieff, M. (2018). Las virtudes cotidianas. Orden moral en un mundo dividido. Madrid: Taurus.

Innes, J. (1995). Planning Theory's Emerging Paradigm: Communicative Action and Interactive Practice. Journal of Planning Education and Research, 14(3), 183-189.

Isidoro de Sevilla, s. (2004). Etimologías. (J. Oroz Reta \& M.-A. Marcos Casquero, Trads.) Madrid: Biblioteca de Autores Cristianos.

Jacobs, J. (2011). Muerte y vida de las grandes ciudades. Madrid: Capitán Swing.

Kirkman, R. (2010). The Ethics of Metropolitan Growth: The Future of our Built Environment. London: Bloomsbury.

Lefebvre, H. (1976). Espacio y política. El derecho a la ciudad II. Barcelona: Península.

Lefebvre, H. (2013). La producción del espacio. Madrid: Capitán Swing.

Lefebvre, H. (2017). El derecho a la ciudad. Madrid: Capitán Swing. 
Lynch, K. (2008). La imagen de la ciudad. Barcelona: Gustavo Gili.

Marcuse, P. (2009). Spatial Justice: Derivative but Causal of Social Injustice. Justice spatiale | Spatial Justice, 1(1), 42-50.

McHarg, I. (2000). Proyectar con la naturaleza. Barcelona: Gustavo Gili.

Mitchell, W. J. (2000). City of Bits: Space, Place, and the Infobahn. Cambridge, MA: MIT Press.

Mongin, O. (2006). La condición urbana. La ciudad a la hora de la mundialización. Barcelona: Paidós.

Mostafavi, M. (2017). Ethics of the Urban: The City and the Spaces of the Political. Cambridge, MA; Zürich: Harvard University Graduate School of Design; Lars Müller Publisher.

Mouffe, C. (2007). En torno a lo político. México: Fondo de Cultura Económica.

Mugerauer, R., Manzo, L. (2008). Environmental Dilemmas: Ethical Decision Making. Lanham: Lexington.

Musset, A. (ed.) (2010). Ciudad, sociedad, justicia. Un enfoque espacial y cultural. Mar del Plata: EUDEM.

Ostrom, E. (2000). El gobierno de los bienes comunes. México: Fondo de Cultura Económica.

Owen, G. (ed.). (2009). Architecture, Ethics and Globalization. London: Routledge.

Peattie, L. (1987). Planning: Rethinking Ciudad Guayana. Ann Arbor: University of Michigan Press.

Ramírez, J. L. (1998). Los dos significados de la ciudad o la construcción de la ciudad como lógica y como retórica. Scripta Nova: Revista electrónica de geografía y ciencias sociales (2), 14-31.

Rose, J. F. (2018). La ciudad bien temperada. Qué nos enseñan la ciencia, las antiguas civilizaciones y la naturaleza humana sobre el futuro de la vida en las ciudades. Barcelona: Antoni Bosch.

Sennett, R. (2006). La cultura del nuevo capitalismo. Barcelona: Anagrama.

Sennett, R. (2019). Construir y habitar. Ética para la ciudad. Barcelona: Anagrama. 
Soja, E. (2008). Postmetrópolis. Estudios críticos sobre las ciudades y las regiones. Madrid: Traficantes de Sueños.

Soja, E. (2014). En busca de la justicia espacial. Valencia: Tirant lo Blanch.

Spector, T. (2001). The Ethical Architect: The Dilemma of Contemporary Practice. New York: Princeton Architectural Press.

Sudjic, D. (2007). La arquitectura del poder. Cómo los ricos y poderosos dan forma a nuestro mundo. Barcelona: Ariel.

Susskind, L., Cruikshank, J. (1987). Breaking the Impasse: Consensual Approaches to Resolving Public Disputes. New York: Basic Books.

Throgmorton, J. A. (1991). The Rhetorics of Policy Analysis. Policy Sciences, 24(2), 153-179.

Wacquant, L. (2007). Los condenados de la ciudad. Gueto, periferias y Estado. Buenos Aires: Siglo Veintuno Editores.

Wasserman, B., Sullivan, P., Palermo, G. (2000). Ethics and the Practice of Architecture. New York: John Wiley and Sons.

Young, I. M. (2000). La justicia y la política de la diferencia. Madrid: Cátedra. 